\title{
Effects of Cement-Modified Soil as Blocking Cushion of Saline Soil Subgrade
}

\author{
Tianwen Lai*, Hao Lei, Zhiyang Ji, Yu Liang \\ School of Civil Engineering, Lanzhou Jiaotong University, Lanzhou 730070, China
}

Corresponding Author Email: laitianwen@mail.lzjtu.cn

https://doi.org/10.18280/rcma.300108

Received: 15 August 2019

Accepted: 24 November 2019

\section{Keywords:}

cement-modified soil (CMS), saline soil, cushion, partition, pile-soil stress ratio

\begin{abstract}
This paper puts forward a novel approach called cement-modified soil (CMS) blocking cushion technology to reinforce the subgrade in saline soil region: the cushion layer of composite foundation and a roadbed partition layer are combined into one CMS layer. The effectiveness of the proposed approach was verified through outdoor experiments on the saline soil section (DK821+600-DK821+900) of the newly built Lanxin High-Speed Railway. The experimental results show that the CMS layer can effectively adjusts the pile-soil stress ratio of the composite foundation, thereby enhancing the bearing capacity of the composite foundation and reducing the total settlement of the subgrade; it is also verified that the CMS layer greatly suppresses the upward migration of capillary water and water vapor in the foundation soil, and curbs the migration of salt, preventing the secondary salinization of the railway subgrade. Overall, this research provides a simple and low-cost subgrade reinforcement technique for saline soil regions, shedding new light on the engineering application of the CMS.
\end{abstract}

\section{INTRODUCTION}

Since its birth in the 1940 s, cement-modified soil (CMS) has been immensely popular among engineers and researchers. The recent research on the CMS mainly focuses on engineering properties and application. In terms of engineering properties, most scholars have emphasized on the mechanical properties of the CMS. For instance, Consoli et al. [1-5] explored the strength and stiffness of Portland cement mixture and their relationships with molding moisture content and porosity, and also investigated the durability, strength and stiffness of green stabilized sand and fiber-reinforced compacted cement-gold tailings blends. Subramanian et al. [6] analyzed the microstructure and strength development of artificial sand treated with calcium sulfoaluminate (CSA). Cui et al. [7] studied the effects of the curing age and freeze-thaw cycle on the mechanical properties of the CMS. Nguyen et al. [8] conducted a phase field simulation of early-breaking cement-based materials.

In terms of engineering application, there are two main research directions: improving and solidifying various soils with cement as curing agent; exploring the CMS mechanisms and their effects. For example, cement has been adopted to ameliorate fine-grained red clay [9] and grassroots soil [10], and solidify stable contaminated soil [11-13] and high organic matter soil [14]. Many scholars [15-19] blended cement, soil, water and admixtures in different ratios into a multi-phase mixture through uniform mixing, mechanical compaction and curing, applied the mixture to various aspects of foundation treatment (e.g. CMS replacement layer, CMS mixing pile, CMS rotary jet pile), and analyzed the construction process/technique, bearing capacity and seismic response of the treated foundations.

However, the CMS is prone to brittle failure under pressure, which limits its curing effect on clay and organic soil with a high plasticity index. The development and application of the CMS are further bottlenecked by the rapid decline of the bearing capacity after the yield limit is overcome. Considering these defects, this paper attempts to apply the CMS to reinforce the saline soil subgrade.

There are two problems with subgrade in saline soil region: the saline soil is too weak to be used directly as the subgrade foundation, and the road often suffers from secondary salinization. In engineering practice, composite foundation is often adopted to reinforce the foundation of the weak saline soil subgrade. The bearing capacity of composite foundation related to the cushion, which adjusts the pile-soil stress ratio to distribute the load reasonably between the pile and the soil between piles [20]. Meanwhile, the secondary salinization mainly arises from the interaction and migration of water, heat and salt as well as the rise and migration of capillary water vapor in saline soil [21-26]. This phenomenon can be curbed by controlling the water and salt migration with partitions.

Taking the saline soil section (DK821+600-DK821+900) of the newly built Lanxin High-Speed Railway for example, this paper attempts to reinforce the saline soil and prevent secondary salinization with cement-fly ash-gravel (CFG) pile composite foundation and CMS-based partition technology. To save cost and simplify the structure, the cushion layer of the composite foundation and the partition layer were combined into one structural component. Hence, our approach is named CMS blocking cushion technology. Firstly, the 1.0thick saline soil was removed, and the soft soil was treated by the CFG pile. Next, a 1m-thick CMS blocking cushion was placed atop the CFG pile composite foundation. Besides, a layer of unidirectional one-time stretched plastic geogrid was laid laterally in the cushion layer to enhance the CMS resistance to brittle failure. The cement content of the geogrid 
is $5 \%$ in dry mass ratio. The CMS partition covers the area within $3.0 \mathrm{~m}$ outside the unprotected slope. On this basis, outdoor experiments were carried out on the target section to verify whether our CMS blocking cushion technology could effectively adjust the pile-soil stress ratio, and block the water and salt migration.

\section{OVERVIEW OF THE TEST SECTION}

The stratum of the test section is mainly Quaternary flushing, alluvial silt, silty clay, gravel sand and silt. Groundwater depth is about $4 \mathrm{~m}$. The CFG pile composite foundation is used for foundation treatment. The CFG pile plane is arranged in an equilateral triangle with a pile length of $25 \mathrm{~m}$, a pile diameter of $0.5 \mathrm{~m}$ and a pile spacing of $1.7 \mathrm{~m}$. The $1 \mathrm{~m}$ thick CMS layer is used as a cushion for the composite foundation, and also serves as a partition layer for partitioning the lower layer to transpire water vapor and capillary water. The subgrade fill height and the preloading stack height are $9.6 \mathrm{~m}$.

\section{STUDY ON THE CUSHION EFFECT OF CMS PARTITION CUSHION}

\subsection{Test component placement and test frequency}

Three test sections DK821+663, DK821+763, DK821+863 were arranged in the test section. Select several piles in different positions in each section, select 5 piles in sections 663 and 863, and select 7 piles in section 763. A total of seven earth pressure boxes are arranged on the pile top and the soil between the piles (Figure 1). The measured value of each earth pressure box represents the stress value of the area.

The test frequency is determined by the speed of filling the embankment. During the filling process, the reading of the earth pressure box is read every time one layer of soil is filled; if the filling is discontinuous, there is a pause, and the reading is performed every 12 hours.

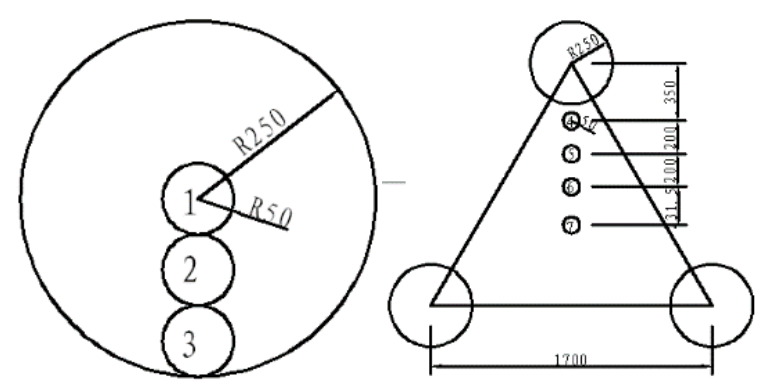

(a) Pile top

(b) Soil between piles

Figure 1. Schematic diagram of earth pressure box arrangement on pile top and soil between piles (unit: $\mathrm{mm}$ )

\subsection{Analysis and results of test data}

First, each pre-embedded earth pressure box is calibrated to obtain a stress-frequency calibration curve. Calculate the earth pressure value of the part of the earth pressure box at the filling height of different embankments according to the actual measured frequency values of the earth pressure boxes at different embankment filling heights, that is, the pile top stress values and the inter-pile soil stress values at different embankment filling heights.

3.2.1 Changes of pile top stress and the soil stress between piles at different fill heights

The stress distribution maps of different parts of a singlepile composite foundation unit are shown when plotting soil stress and pile top stress curve (Figure 2) and different embankment heights at different fill heights (Figure 3).

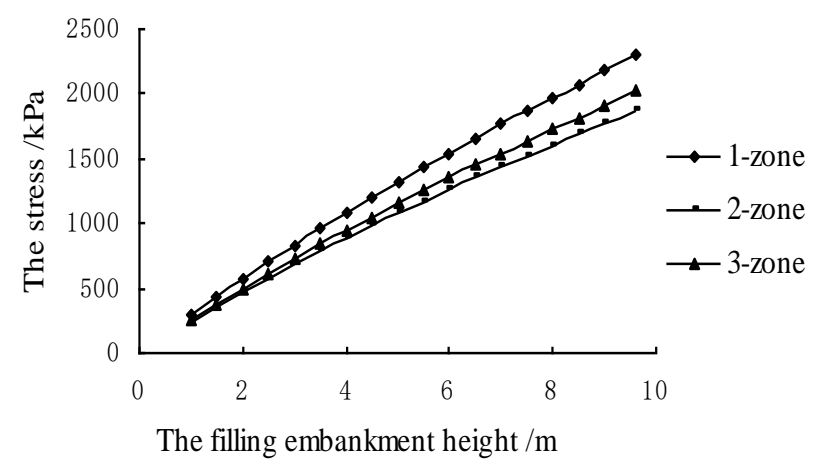

(a) Pile top stress

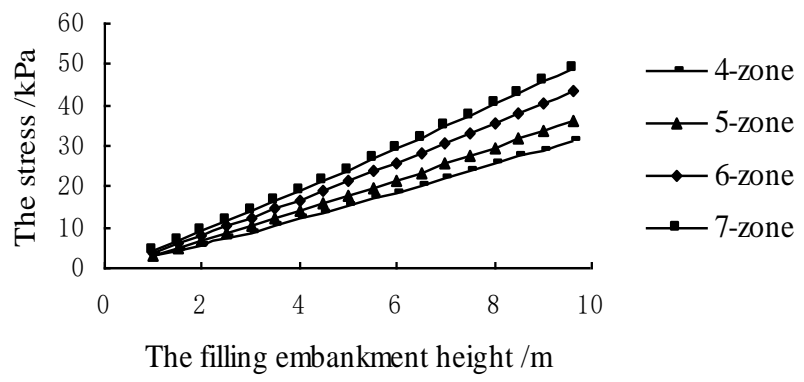

(b) Soil stress between piles

Figure 2. The stress change curve at different embankment filling height

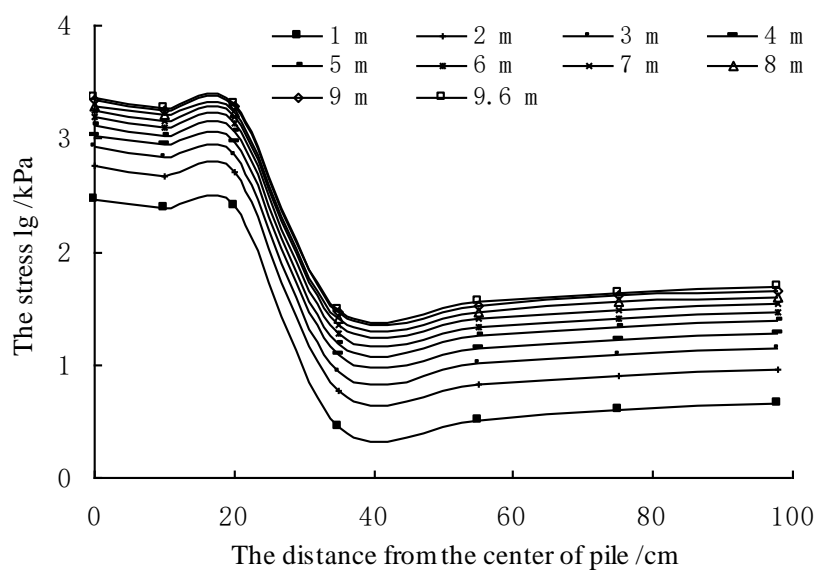

Figure 3. Stress distribution at different distances from the pile center at different embankment filling heights

When drawing, the embankment fill height is converted into the stress value according to the fill density of the fill. Here, only the test data of the 763 section center pile composite foundation unit is selected for analysis.

It can be seen from Figure 3 that with the increasing height of embankment filling, the stresses in the soil between the piles and the pile top are increasing, but its increase is not synchronous. Overall, the increase in soil stress between piles is gradually increasing, while the increase in pile top stress is 
gradually decreasing. At each filling height of each level, the pile top stress value of the same single pile composite foundation unit is always higher than the soil stress value between piles. In the soil between piles or on the top of the pile, the distance from the center of the pile is different, and the stress values are also different. On the soil between piles, the farther away from the center of the pile, the greater the stress, that is, the soil is the closer the center of the pile, the greater the stress; on the top of the pile, the stress in the center of the pile is the largest, and the stress in the edge of the pile is the second. The inter-stress is minimal.

\subsubsection{Changes in pile-soil stress ratio at different embankment} fill heights

According to the measured values of the earth pressure boxes on a single pile composite foundation unit and the area of each earth pressure box representative area, the average pressure of the pile top and the average stress of the soil between piles are calculated, thereby calculating the pile-soil stress. ratio. The data of a single pile composite foundation unit are calculated in each of the three sections, and the variation curve of the pile-soil stress ratio at different fill heights of the embankment is obtained (Figure 4).

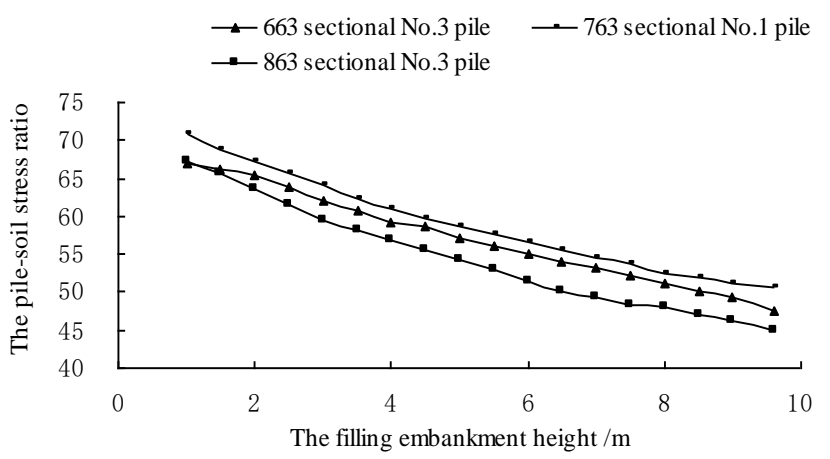

Figure 4. Curve of pile-soil stress ratio at different embankment filling heights

It can be seen from Figure 4 that the subgrade fill height increases from $1 \mathrm{~m}$ to $9.6 \mathrm{~m}$. The pile-soil stress ratio in the left side $1 \#$ pile composite foundation unit of section 663 decreased from 66 to 47 , the pile-soil stress ratio in the central pile composite foundation unit of section 763 decreased from 70 to 51 , the pile-soil stress ratio of $2 \#$ pile composite foundation unit on the right side of section 863 decreased from 66 to 46. With the increase of embankment filling height, the pile-soil stress ratio of single-pile composite foundation units in different sections of the three sections is consistent, and the variation range is basically the same, which gradually decreases with the increase of filling height. At the same fill height, the pile-soil stress ratio of the pile unit nearing the middle line of the embankment is slightly larger than that of the other pile unit. Compared with the measured pile-soil stress ratio under the sandstone cushion, the pile-soil stress ratio under the measured CMS partition is much larger. This is mainly due to the higher bonding strength of the CMS partitioning layer, and the sandstone cushion has substantially no bonding strength. The CMS partition cushion cannot generate fluidity compensation like the gravel cushion, but relies on bending deformation to adjust the pile-soil stress ratio. Under the action of subgrade filling, the self-heavy stress of the filling is first concentrated on the pile with large compressive modulus (compared with the soil between piles) through the CMS partition. With the increase of the filling soil, the displacement between the soil and the pile top of the CMS partition is consistent, which leads to the transfer of the pile top stress to the soil between piles, so that the stress on the soil between piles increases gradually, and the pile top stress gradually decreases. The pile-soil stress ratio is gradually reduced, and the characteristics of the pile-soil shared load are more and more obvious. During the filling process of the entire embankment, the pile-soil stress ratio is always large, which indicates that the CMS partition layer can well exert the stress adjustment effect of the cushion and give full play to the stress bearing effect of the pile body, which is to reduce the total settlement of the composite foundation. It is very beneficial to control the settlement of the roadbed after work.

\section{STUDY ON THE PARTITIONING EFFECT OF CMS PARTITION}

In the DK821+663, DK821+763, DK821+863 three sections, a total of 15 piles of CMS partition mats were selected to embed a moisture sensor and a salt sensor near the top and bottom surfaces of mat, respectively, to measure the moisture content and salt content. Observations began on October 15 of the year, and a total of 648 days were observed. Here, only the test data near the center pile of the 763 section is taken for analysis. The curves of the observed water content and salt content as a function of time are shown in Figure 5 and Figure 6, respectively.

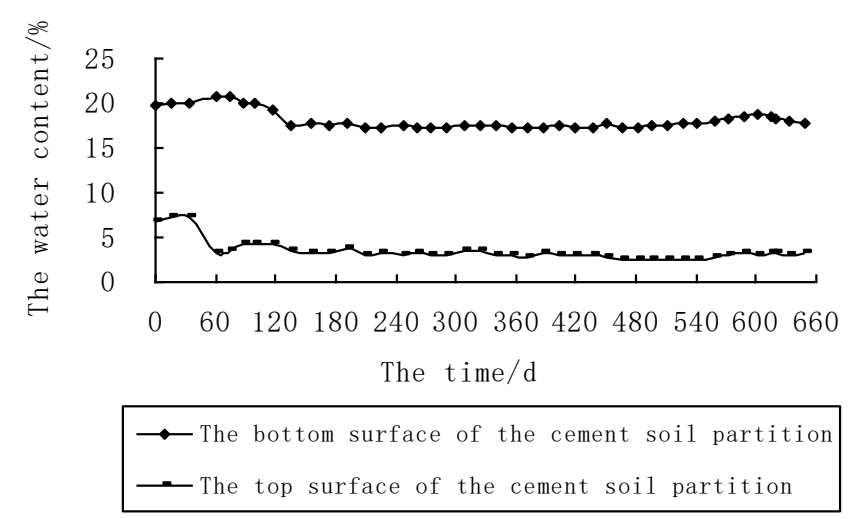

Figure 5. Curve of water content with time near the top and bottom surface of the CMS partition

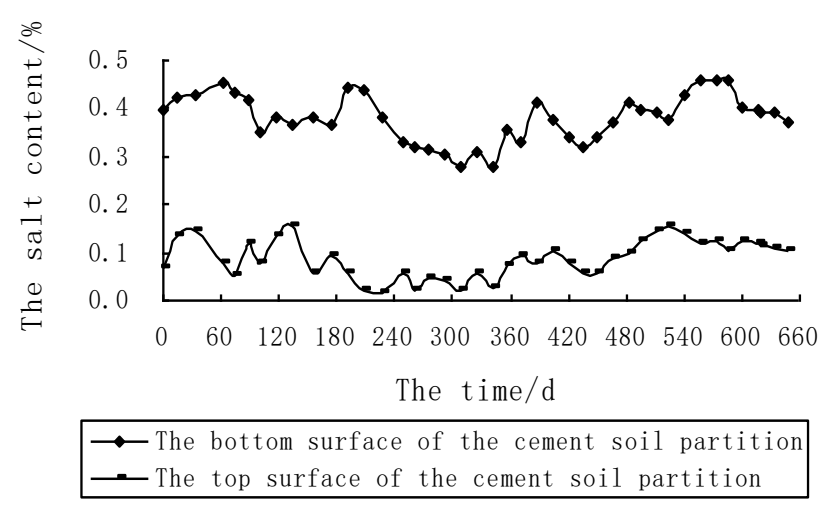

Figure 6. Curve of salt content with time near the top and bottom surface of the CMS partition 
It can be seen from Figure 5 that the water content near the top surface of the CMS block has a slight fluctuation with the season, and the overall tends to be stable. The test point is located in the middle of the subgrade. The initial water content is close to the optimal water content of the packing. The effect of evaporation and rainwater infiltration is relatively weak, so the overall variation of water content is relatively small and relatively stable. The water content near the bottom surface of the CMS partition layer has a process of reducing the water content from mid-December of that year, which lasts about two and a half months, and then remains basically stable. By the end of May of the following year, the water content began to increase again, lasting about 2 months. The water content in this area is the water content in the original natural foundation soil. At the beginning, it is close to the natural water content of the foundation soil. The change of water content at this place is mainly affected by the fluctuation of groundwater level and the action of capillary water, so there is a certain change. In general, at the same time in the same season, the water content near the top surface of the CMS partition is significantly smaller than the water content near the bottom surface of the CMS partition. There is no similarity in the change of water content near the top surface and the bottom surface of the CMS partitioning pad, and they are independent. It can be seen from Figure 6 that the salt content near the top surface of the CMS partition is small, and the maximum is not more than $0.2 \%$. The salt content near the bottom surface of the CMS partition layer is relatively large relative to the top surface, and is between 0.3 and $0.5 \%$. The salt content near the top and bottom of the CMS partition layer increased in winter, but decreased in summer, and the salt content change near the bottom surface was larger than the salt content change near the top surface, but the overall magnitude of change is small. The two changes are not related and are independent. The salt content near the top surface mainly depends on the salt content of the filler and the salt in the rainwater. The salt content near the bottom surface depends on the salt content in the original natural soil and the salt caused by the capillary water in the later stage.

In general, the water content and salt content near the top surface of the CMS partition layer are always significantly smaller than the water content and salt content near the bottom surface of the CMS partition layer. At the same time in the same season, the water content and salt content of the top and bottom surfaces of the CMS barrier are different and independent of each other. It is fully indicated that there is no hydraulic connection between the top surface and the bottom surface of the CMS partitioning layer, and it is confirmed that the CMS partitioning layer has a good partitioning effect, and can effectively block the upward migration of water and salt in the lower layer soil.

\section{CONCLUSION}

Through on-site measurement and theoretical analysis, the following conclusions are drawn:

(1) The CMS layer can well adjust the pile-soil stress ratio. The pile-soil stress ratio of the CFG pile composite foundation under the CMS cushion is much larger than the pile-soil stress ratio under the general sandstone cushion. It shows that the CMS cushion is beneficial to increase the pile-soil stress ratio, and the advantages of large pile strength and high bearing capacity are exerted. It is beneficial to improve the bearing capacity and resistance deformation capacity of the composite foundation as a whole.

(2) The CMS layer has good partitioning effect, which can effectively block the migration of water and salt in the foundation soil, and produce secondary salinization in the basic body of the road.

(3) CMS partitioning cushion is a new type of structural form that effectively combines composite foundation cushion and partition layer technology in saline soil roadbed engineering. This technology can not only solve the problem of weak saline soil foundation reinforcement, but also solve the problem of secondary salinization of road basic body. This technology also expands new directions for the application of CMS materials in engineering.

\section{REFERENCES}

[1] Consoli, N.C., Ferreira, P.M.V., Tang, C.S., Marques, S.F.V., Festugato, L., Corte, M.B. (2016). A unique relationship determining strength of silty/clayey soilsPortland cement mixes. Soils and Foundations, 56(6): 1082-1088. https://doi.org /10.1016/j.sandf.2016.11.011

[2] Consoli, N.C., Quiñónez, R.A., González, L.E., López, R.A. (2017). Influence of molding moisture content and porosity/cement index on stiffness, strength, and failure envelopes of artificially cemented fine-grained soils. Journal of Materials in Civil Engineering, 29(5): 04016277. https://doi.org/10.1061/(ASCE)MT.19435533.0001819

[3] Consoli, N.C., Quiñónez Samaniego, R.A., González, L.E., Bittar, E.J., Cuisinier, O. (2018). Impact of severe climate conditions on loss of mass, strength, and stiffness of compacted fine-grained soils-Portland cement blends. Journal of Materials in Civil Engineering, 30(8): 04018174. https://doi.org/10.1061/(ASCE)MT.19435533.0002392

[4] Consoli, N.C., Winter, D., Leon, H.B., Scheuermann Filho, H.C. (2018). Durability, strength, and stiffness of green stabilized sand. Journal of Geotechnical and Geoenvironmental Engineering, 144(9): 04018057. https://doi.org /10.1061/(ASCE)GT.1943-5606.0001928

[5] Consoli, N.C., Nierwinski, H.P., da Silva, A.P., Sosnoski, J. (2017). Durability and strength of fiber-reinforced compacted gold tailings-cement blends. Geotextiles and Geomembranes, 45(2): 98-102. https://doi.org/10.1016/j.geotexmem.2017.01.001

[6] Subramanian, S., Moon, S.W., Moon, J., Ku, T. (2018). CSA-treated sand for geotechnical application: microstructure analysis and rapid strength development. Journal of Materials in Civil Engineering, 30(12): 04018313. https://doi.org/10.1061/(ASCE)MT.19435533.0002523

[7] Cui, H.W., Pei, G.L., Yao, S.J., Wang, G.Y., Zhang, Z.G. (2018). Experimental study of mechanical properties of CMS of different curing time subjected to freezingthawing cycles. Journal of Glaciology and Geocryology, 40(1): 110-115. https://doi.org/10.7522/j.issn.10000240.2018 .0014

[8] Nguyen, T.T., Waldmann, D., Bui, T.Q. (2020). Phase field simulation of early-age fracture in cement-based materials. International Journal of Solids and Structures, 191-192(5):

157-172. https://doi.org/10.1016/j.ijsolstr.2019.12.003. 
[9] Mengue, E., Mroueh, H., Lancelot, L., Eko, R.M. (2017). Mechanical improvement of a fine-grained lateritic soil treated with cement for use in road construction. Journal of Materials in Civil Engineering, 29(11): 04017206. https://doi.org/10.1061/(ASCE)MT.1943-5533.0002059

[10] Mamun, M.M.H., Ovi, M.F.M., Akhter, F., Barua, S., Ahmed, M., Nipa, T.J. (2016). Improvement of Sub Base Soil Using Sand-Cement Stabilization. American Journal of Civil Engineering, 4(5): 241-246. https://doi.org/10.11648/ j.ajce.20160405.15

[11] Zha, F., Liu, J., Xu, L., Kang, B., Yang, C., Deng, Y. (2020). Solidification/Stabilization $(\mathrm{s} / \mathrm{s})$ of zinc contaminated soils using cement blended with soda residue. Environmental Geotechnics, 1-8. https://doi.org/10.1680/jenge.18.00183

[12] Kogbara, R.B. (2017). Interrelationships among geotechnical and leaching properties of a cementstabilized contaminated soil. Journal of Environmental Science and Health, Part A, 52(2): 149-157. https://doi.org/10.1007/s12665-017-7071-1

[13] Li Y., Jia S., Liu J. (2018). Study on curing mechanism of magnesium phosphate cement to contaminated soil. Chemical Engineering Transactions, 66: 1207-1212. DOI:10.3303/CET1866202.

[14] Lemos, S.G.P., Almeida, M.D.S.S., Consoli, N.C., Nascimento, T.Z., Polido, U.F. (2020). Field and laboratory investigation of highly organic clay stabilized with portland cement. Journal of Materials in Civil Engineering, 32(4): 04020063 https://doi.org/10.1061/(ASCE)MT.1943-5533.0003111

[15] Ishikura, R., Yasufuku, N., Brown, M.J. (2016). An estimation method for predicting final consolidation settlement of ground improved by floating soil cement columns. Soils and Foundations, 56(2): 213-227. https://doi.org/10.1016/j.sandf.2016.02.005

[16] Phutthananon, C., Jongpradist, P., Yensri, P., Jamsawang, P. (2018). Dependence of ultimate bearing capacity and failure behavior of $\mathrm{T}$-shaped deep cement mixing piles on enlarged cap shape and pile strength. Computers and Geotechnics, 97: 27-41. https://doi.org/10.1016/j.compgeo.2017.12.013

[17] Wu, Y., Zhang, K., Fu, L., Liu, J., He, J. (2019). Performance of cement-soil pile composite foundation with lateral constraint. Arabian Journal for Science and Engineering, $44(5)$ : 4693-4702. https://doi.org/10.1007/s13369-018-3519-1

[18] Ni, P., Yi, Y., Liu, S. (2020). Bearing capacity of composite ground with soil-cement columns under earth fills: Physical and numerical modeling. Soils and Foundations, 59(6): 2206-2219. https://doi.org/10.1016/j.sandf.2019.12.004

[19] Yamashita, K., Shigeno, Y., Hamada, J., Chang, D.W. (2018). Seismic response analysis of piled raft with gridform deep mixing walls under strong earthquakes with performance-based design concerns. Soils and Foundations, $\quad$ 58(1): 65-84. https://doi.org/10.1016/j.sandf.2017.12.002

[20] Yan, S.W., Lang, R.Q., Sun, L.Q., Chen, J., Jia, Z.L. (2017). Calculation of pile-soil stress ratio in composite foundation with rigid pile-net based on plate theory. Chinese Journal of Rock Mechanics and Engineering, 36(8): $2051-2060$ https://doi.org/10.13722/j.cnki.jrme.2016.1472

[21] Lekakis, E.H., Antonopoulos, V.Z. (2015). Modeling the effects of different irrigation water salinity on soil water movement, uptake and multicomponent solute transport. Journal of Hydrology, 530(11): 431-446. https://doi.org/10.1016/j.jhydrol.2015.09.070

[22] Tounsi, H., Rouabhi, A., Jahangir, E. (2020). Thermohydro-mechanical modeling of artificial ground freezing taking into account the salinity of the saturating fluid. Computers and Geotechnics, 119: 103382. https://doi.org/10.1016/j.compgeo.2019.103382

[23] Litalien, A., Zeeb, B. (2020). Curing the earth: A review of anthropogenic soil salinization and plant-based strategies for sustainable mitigation. Science of the Total Environment, 698(1): 134235. https://doi.org/10.1016/ j.scitotenv.2019.134235

[24] Rouabhi, A., Jahangir, E., Tounsi, H. (2018). Modeling heat and mass transfer during ground freezing taking into account the salinity of the saturating fluid. International Journal of Heat and Mass Transfer, 120: 523-533. https://doi.org/10.1016/j.ijheatmasstransfer.2017.12.065

[25] Callaghan, M.V., Head, F.A., Cey, E.E., Bentley, L.R. (2017). Salt leaching in fine-grained, macroporous soil: Negative effects of excessive matrix saturation. Agricultural Water Management, 181(2): 73-84. https://doi.org/10.1016/j.agwat.2016.11.025

[26] Wei, K., Zhang, W., Liu, X., Ren, X.L., Li, S.W., Wen, Y. (2016). Effects of particle size distribution on capillary water upward movement in saline soil of Eastern Qinghai area. Journal of Qinghai University (Natural Science Edition), 34(3): 1-8. https://doi.org/10.13901/j.cnki.qhwxxbzk.2016.03.001 